\title{
Research Progress On Comprehensive Utilization Of Fruit And Vegetable Waste
}

\author{
Wanyun Penga ${ }^{\mathrm{a}}$, Qianqian $\mathrm{Ma}^{\mathrm{b}}$, Zhide Wang ${ }^{\mathrm{c}}$, Zhengwei Xie ${ }^{\mathrm{d}}$ \\ Dazhou Academy of Agricultural Sciences, Dazhou, Sichuan, China
}

\begin{abstract}
Random stacking and inefficient treatment of fruit and vegetable waste is one of the main reasons for environmental pollution and resource waste, and the research on its resource utilization has become the first problem to be solved. This paper reviews the research progress of fruit and vegetable waste in energy, fertilizer and feed utilization in order to provide reference for resources utilization of fruit and vegetable waste in China.
\end{abstract}

\section{Introduction}

With the rapid development of intensive agricultural planting, the output of fruit and vegetable waste has increased sharply in recent years [1]. In India, up to $5.6 \mathrm{x}$ $10^{6}$ tons of fruit and vegetable waste is generated annually, most of which are stacked on the edge of the city [2]. In China, fruit and vegetable waste accounts for $20 \%$ and $50 \%$ of municipal solid waste, and the annual output of fruit and vegetable waste accounts for $25 \%-30 \%$ of the total output of fruits and vegetables. About 100 billion tons of fruit and vegetable waste is discarded every year [3]. Because of its high moisture content, fruit and vegetable waste is not suitable for incineration process; at the same time, due to the high content of organic components, a large number of leachate will be produced by stacking or landfill, resulting in serious environmental pollution [4].

Therefore, how to turn fruit and vegetable waste into treasure and resource utilization is particularly important. This paper summarizes the research progress of fruit and vegetable waste in energy utilization, fertilizer utilization, feed utilization and other resource utilization, in order to provide ideas and reference for the innovation and application of efficient utilization of fruit and vegetable waste.

\section{Source and characteristics of fruit and vegetable waste}

\subsection{Source of fruit and vegetable waste}

From seedling raising to maturity, from harvest to listing, and then to processing, every link will produce waste. The main sources of fruit and vegetable waste are fruit and vegetable production area, fruit and vegetable distribution center and fruit and vegetable processing area and so on. According to statistics, 1.2 million tons of vegetable waste are generated every year in 53300 hectares of facility vegetable base in Shouguang area, Shandong Province [5]. In the peak season of vegetable production and sales in May and October of each year, the daily output of vegetable garbage in Beijing Xinfaodi Agricultural products Wholesale Market is about 180 tons, accounting for more than $90 \%$ of the total [6]. In the process of processing, the loss rate of leafy vegetables is the highest, and the highest loss rate is $60 \%$ in summer [7].

\subsection{Characteristics of fruit and vegetable waste}

Fruit and vegetable waste is not suitable for long-distance transportation, short storage time, putrescibility, low $\mathrm{pH}$ value, high moisture content, the total solid content is generally $8 \%-18 \%$, in which volatile solids account for about $87 \%$ of the total solid content; organic matter includes $75 \%$ sugar and hemicellulose, $9 \%$ cellulose and $5 \%$ lignin, $\mathrm{N}, \mathrm{P}, \mathrm{K}$ and other nutrient elements are rich, basically non-toxic [8]. Therefore, it is necessary to make use of fruit and vegetable waste.

\section{Treatment method of fruit and vegetable waste}

\subsection{Anaerobic fermentation technology}

Anaerobic digestion is the main means of energy utilization. The anaerobic digestion treatment organic waste has the advantages of high benefit, and can be used for recycling clean energy. The results show that the water content of vegetable waste is high, it is easy to degrade, its chemical oxygen demand and nitrogen ratio are between the requirements of methane-producing microorganisms, and the anaerobic digestion is especially suitable for the treatment of vegetable waste [9-10]. Anaerobic digestion includes batch system, continuous flow single-phase digestion system and continuous flow two-phase system. 
Scholars have studied three digestive systems, Table 1

treatment of reaction performance in each study is listed. shows the gas production of some of the studies. The best

Table 1 Gas production in some studies

\begin{tabular}{cccccc}
\hline Type of reaction system & $\begin{array}{c}\text { OLR } \\
(\mathrm{gVS} / \mathrm{L} \cdot \mathrm{d})\end{array}$ & HRT(d) & $\begin{array}{c}\text { Removal } \\
\text { rate of VS } \\
(\%)\end{array}$ & $\begin{array}{c}\text { Yield of CH4 } \\
(\mathrm{L} / \mathrm{g} \bullet \mathrm{VS})\end{array}$ & reference \\
\hline $\begin{array}{c}\text { Batch digestive system } \\
\begin{array}{c}\text { Continuous flow single-phase } \\
\text { digestive system }\end{array}\end{array}$ & 1.33 & 30 & 86 & 0.22 & {$[11]$} \\
Continuous flow two-phase system & $\begin{array}{c}1.6 \\
\mathrm{COD} / \mathrm{L} \cdot \mathrm{d}\end{array}$ & 20 & 88 & 0.47 & {$[12]$} \\
\hline
\end{tabular}

\subsubsection{Batch digestive system}

Batch digestion system refers to the addition of feed to the reactor at one time and the addition or absence of microbial agents according to the experimental conditions. Each step of anaerobic digestion is carried out in the reactor in turn. Garcia-Pena et al studied the effects of controlling $\mathrm{pH}$ value and adding nitrogen on the anaerobic digestion performance of fruit and vegetable waste in batch system. The results showed that controlling $\mathrm{pH}$ value and adding nitrogen could significantly improve the performance of the system [14]. Garcia-Pena et al studied the effects of controlling $\mathrm{pH}$ value and adding nitrogen on the anaerobic digestion performance of fruit and vegetable waste in batch system. The results showed that controlling $\mathrm{pH}$ value and adding nitrogen could significantly improve the performance of the system. The yield of methane was $0.42 \mathrm{~m} 3 \cdot \mathrm{kg}$, the content of methane was $50 \%$, and the degradation rate of volatile solid was $80 \%$. The results showed that the yield of biogas was $0.42 \mathrm{~m}^{3} / \mathrm{kg}$, the content of methane was $50 \%$, and the degradation rate of volatile solid was $80 \%[15]$. Batch digestion system has the characteristics of simple design, convenient control, high pollution degree waste treatment and low investment. Therefore, it is especially suitable for use in developing countries.

\subsubsection{Continuous flow single-phase digestive system}

Single-phase digestive system is the main way to deal with municipal solid waste in the world at present, its operation is simple and the cost is low. Many scholars use different single-phase digestive systems to treat fruit and vegetable waste. When fruit and vegetable waste is treated by continuous stirred tank reactor (CSTR), $\mathrm{pH}$ will decrease obviously, and the content of $\mathrm{CO}$ in biogas will increase [16]. Mata-Alvarez et al. used a single phase reaction stirrer at room temperature to treat waste from large vegetable market [17].

\subsubsection{Continuous flow two-phase system}

The advantages of two-phase digestion system mainly include the accumulation of volatile organic acids and buffering of $\mathrm{pH}$ value, short total hydraulic retention time and reaction time, high load, high gas production and high methane production. Bouallagui et al studied the anaerobic digestion of fruit and vegetable waste by two combined anaerobic programmed batch reactors at room temperature. The results showed that fruit and vegetable waste could be highly biodegraded in the traditional two-phase reactor, and $96 \%$ of the total COD in the reaction could be converted into biogas and biomass [18].

\subsection{Anaerobic fermentation technology}

Composting, as an effective fertilizer treatment technology for organic waste, has become a hot research topic in solid waste resource utilization at home and abroad. Aerobic composting has a high temperature, generally $50^{\circ} \mathrm{C}-65^{\circ} \mathrm{C}$, so it is also called high temperature composting. High temperature composting can kill pathogenic bacteria to the maximum extent and degrade organic matter rapidly. It is an effective method to treat organic waste. Aerobic composting includes direct composting of fruit and vegetable waste and mixed landfill of fruit and vegetable waste and feces.

\subsubsection{Direct composting method of fruit and vegetable waste}

John et al compared four low-tech supermarket waste composting methods (underground cellar, open underground, closed on the ground). Through the verification of each index, it is found that the maturity progress of closed compost on the ground is better than that of the other three methods [19]. Kostov et al filled all kinds of fruit and vegetable waste with aerobic landfill, and then applied it to cucumber planted in greenhouse. It was found that the nutritional composition of cucumber with landfill was higher than that of cucumber with common fertilizer, the application of the landfill cucumber is 10-12 days earlier than the other early maturity, and the yield was also higher than that of common landfill, which reflected the higher economic benefit of fruit and vegetable waste [20].

\subsubsection{Mixed composting method of fruit and vegetable waste and feces}

Alkoaik et al. used a laboratory specification bioreactor to carry out the experimental study on the mixture of tomato waste and cow manure. The results show that the addition of cow manure can provide a large amount of elements 
and trace elements needed for the microorganisms needed for composting, which can reduce the stagnation time and accelerate the composting process[21]. Guan Huilin et al, using vegetable rhizome and flower straw waste, fresh pig manure and organic saprophyte as raw materials, were treated with mixed compost in different proportion to return to the field. It is found that the addition of organic saprophyte can promote the rapid degradation of solid waste and improve the utilization rate of returning to the field [22].

\subsection{Other treatment methods}

\subsubsection{Method of producing feed protein by solid fermentation}

In the early stage of the development of animal husbandry in China, the vegetable waste of the rural households is often directly fed to animals such as pigs, sheep and chickens, which plays an important role in the development of animal husbandry in China at that time. However, in the process of direct feeding, the combination of lignin and sugar in fruit and vegetable waste will increase the difficulty of decomposing microorganisms and enzymes in rumen of animals, and direct feeding can not be absorbed and utilized by animals efficiently. In addition, the direct raising of livestock and poultry with pests and diseases may endanger animal health [23]. With the development of science and technology, researchers use biological or physical technology to treat vegetable waste, and convert sugar, protein, hemicellulose, cellulose and other substances in vegetable waste into feed [24-25]. At present, the main feeding methods are silage and processing feed protein, feed powder and so on. Zhang Ji, et al. takes the waste of high mountain doll as the main raw material, uses the non-sterile solid fermentation process to produce the feed crude protein, and determines the optimal combination of the fermentation and the optimal inoculation amount, and the inoculation proportion [26]. Shen Haiyu et al fed ducklings with broccoli stem and leaf feed powder. It was found that the addition of broccoli stem and leaf feed powder significantly increased the activities of amylase and trypsin, thus improving the digestive performance of ducklings [27].

\subsubsection{Adsorption capacity utilization method}

A large number of agricultural and forestry wastes are produced every year in the food processing industry. These solid wastes are rich in lignocellulose resources such as cellulose, hemicellulose, lignin and so on. They can be used as high quality adsorbents for sewage treatment [28]. Scholars at home and abroad have found that biomass materials have strong adsorption capacity for heavy metal ions, methylene blue and so on, and the adsorption effect is better after modification [29-31]. Chen Yimin et al used solid waste produced by a freeze-dried fruit and vegetable production enterprise to treat wastewater containing hexavalent chromium ion, copper ion and methylene blue. The results show that fruit and vegetable solid waste has good adsorption effect on hexavalent chromium ion, copper ion and methylene blue, which can be used as pretreatment of industrial wastewater treatment, which can greatly reduce the burden of subsequent sewage treatment and ensure the stability of effluent [32].

\section{Thinking and Prospect}

Compared with other solid wastes, fruit and vegetable waste has obvious special properties. Since 1980s, foreign countries have begun to carry on the special research to the fruit and vegetable waste treatment method, which mainly has the aerobic heap fertilizer, the anaerobic digestion, the aerobic and anaerobic combined treatment and the production feed and so on. In recent years, a lot of research has been carried out on the utilization of fruit and vegetable waste resources in China, and the achievements have been applied to production to realize the utilization of fruit and vegetable waste resources.

However, there are still many limitations in the application equipment, application technology and application mode. In order to further explore the development model suitable for the national conditions of our country, combined with the source and characteristics of fruit and vegetable waste in our country, the suitable resource utilization methods can be optimized or developed in order to realize the purpose of cleaner production and efficient utilization of resources. First, according to the local conditions, select the appropriate or innovative treatment method (one or more mixed-mix) according to the regional, kind and seasonal characteristics of the source of fruit and vegetable waste.The fruit and vegetable waste produced by Beijing Xinfa Fruit and vegetable Wholesale Market has been treated, and its resource products have been upgraded from a single ordinary compost to high value-added leaf fertilizer and biomass natural gas (instead of gasoline). Shanghai, Beijing and other places used aerobic composting as vegetable base fertilizer and large-scale biogas fermentation combined with livestock and poultry feces[33]. The second is to draw lessons from the advanced experience of vegetable waste utilization in developed countries, increase the intensity of supporting process research and equipment research and development, encourage the development and application of efficient production equipment, and promote the technological innovation and equipment level of waste treatment. The research on technology related to production of liquid fertilizer will lay a solid foundation for popularizing the high-efficiency, light simplification and automatic utilization mode of fruit and vegetable waste. Third, the government supports, first of all, in the typical main fruit and vegetable production areas and large fruit and vegetable distribution centers to establish appropriate waste treatment centers, demonstrate the application of vegetable waste resources efficient utilization model; support the development of vegetable waste resources related enterprises, strengthen fruit and vegetable production parks, wholesale markets and agricultural products processing plants to cooperate with enterprises, 
increase publicity, increase the awareness of enterprise and personal resource utilization.

\section{References}

1. J. Lin, J. Zuo, L.L. Gan, et a1. Effects of mixture ratio on anaerobic co-digestion with fruit an d vegetable waste and food waste of China $[\mathrm{J}]$. Journal of Environmental Sciences, 23(8): 1403-1408.

2. V. NaUatbambi Gunaseelan. Biochemical nmthane potential of fruits and vegetable solid waste feedstocks [J]. Biomass and Binenergy, 2004, 26: 389-399.

3. G.M. Liu, Y.L. Dong, J.L. Xue, et al. Characteristics of anaerobic digestion of fruit and vegetable waste and solid decrement [J]. Environmental Science \& Technology, 2009, 32(03): 27-30.

4. Viturtia A M, Mata-Alvarez J, Cecchi F, Fazzini G. Two-phaseanaerobic digestion of a mixture of fruit and vegetable wastes[J]. Biol Wastes. 1989, 29: 89-99.

5. P.Z. Li. Treatment measures and effects of Shouguang vegetable waste $[\mathrm{J}]$. China Vegetables, 2017(3): 13-15.

6. S.Y. Liu, W. Li, W.J. Li, et a1. Anaerobic fermentation biotechnology of fruit and vegetable waste treatment and its future prospect $[\mathrm{J}]$. Agricultural Outlook. 2013, 9(10): 58-61.

7. J.J. Li, G.Y. Zou, Q.P. Sun, et a1. Study on physical and chemical properties and maturity of liquid fertilizer from vegetable waste during retting [J]. Chinese Agricultural Science Bulletin, 2012, 28(13): 264-270.

8. Bouallagui H, Touhami Cheikh R B, et a1. Bioreactor performance in anaerobic digestion of fruit and vegetable wastes [J]. Process Biochem istry, 2005, 40 989-995.

9. D.G. Huang, W.J. Lu, H.T. Wang. Progress on study of agricultural vegetable waste treatment [J]. Techniques and Equipment for Environmental Pollution Control, 2002, 3(11):38-42.

10. Bouallagui H, Touhami Y, Cheikh R B, Hamdi M.Bioreactor performance in anaerobic sigestion of fruit and vegetable wastes [J]. Process Biochemistry, 2005, 36(19): 989-995.

11. Conveai A, DelBorghi A, Zilli M, et a1. Anaerobic digestion ofthe vegetable fraction of municipal refuses: mesophilic versus thermophilic conditions [J]. Bioprocess Eng, 1999, 21:371-376.

12. Bouallagui H, Touhami Y, Ben Cheikh R, et a1. Bioreactor performance in anaerobic digestion of fruit and vegetable wastes [J]. Process Biochemistry, 2005, 40: 989-995.

13. Bouallagui $\mathrm{H}$, Torrijos $\mathrm{M}$, Godon $\mathrm{J} \mathrm{J}$, et a1. Two-phases anaerobic digestion of fruit and vegetable wastes : bioreactors performance [J]. Biochemical Engineering, 2004, 21:193-197.

14. Garcia-Pena E I, Parameswaran P, D W Kang et a1.
Anaerobic digestion and co-digestion processes of vegetable and fruit residues:Process and microbial ecology [J]. ioresource Technology, 2011(02): 9447-9455.

15. Garcia-Pena E I, Parameswaran P, Kang D W et a1. Anaerobic digestion and co--digestion processes of vegetable and fruit residuesProcess and microbial ecology [J]. Bioresource Technology, 201 , 102:9447-9455.

16. Lane A G. Methane from anaerobic digestion of fruit and vegetable processing waste [J]. Food Technol, 1979, 31:201-207.

17. Mata-Alvarez J, Cecchi F, Llabr\& P, Pavan P. Anaerobic digestion of the Barcelona central food market organic wastes : experimental study [J]. BioresourTeehnol, 1992, 39: 39-48.

18. Bouallagui H, Torrijos M, Godon J J, et a1. Two phases anaerobic digestion of fruit and vegetable wastes:bioreactors perforrnance $[\mathrm{J}]$. Biochemical Engineering, 2004, 21: 193-197.

19. John B, John S, Erasmus O, et a1. Comparison of four low technology composting methods for market crop wastes [J]. Waste M anagem ent, 2009, 29:274-2281.

20. Kostov O, Tzvetkov Kaloianova N, et a1. Cucumber cultivation on some wastes during their aerobic composting [J]. Bioresource Technology, 1995, 53:237-242.

21. Alkoaik F, Ghaly A E. Influence of dairy manure addition on the biological an $d$ therm al kinetics of composting of greenhouse tomato plant residues [J]. Waste Management, 2006, 26: 902-913.

22. H.L. Guan, Y.F. Zhang, W.D. Zhang, et a1. Utilization of agricultural residues with biological treatment in dianchi lake basin $[\mathrm{J}]$. Journal of Agro-Environment Science, 2006(S2):625-628.

23. Z.Y. Chen, D.G. Shi, E.X. Wang. Development of the application of resource utilization technology in agricultural waste $[\mathrm{J}]$. China Population Resources and Environment, 2010, 20(12): 112-116.

24. M. Li, H.X. Wang, summary of comprehensive utilization measures of agricultural waste [J]. China Population Resources and Environment, 2012, 22(S1): 37-39.

25. R.X. Qi, T. Wei, M.Z. Wang, et a1. Technologies of Feed Utilization for Vegetable Waste and Its Application in Livestock and Poultry Prpduction [J]. Chinese Journal of Animal Nutrition, 2018, 30(04): 1297-1302.

26. J. Zhang, G.P. Wu, Y.X. Gao, et a1. Feeding-protein producing by solid-fermentation from vegetable wastes [J]. Journal of Northwest Normal University(Natural Science), 2007(04): 85-89.

27. H.Y. Shen, L. Yang, C. Han, et a1. Effect of feeding application of broccoli stem and leaf powder on digestive performance of ducklings $[\mathrm{J}]$. Journal of Kaili University, 2016, 34(03): 70-73.

28. S. Jiang, L.L Nv, W.H. Guo. Research progress on 
treatment technique for fruit and vegetable wastes [J]. Natural Product Research and Development, 2017, 29(01): 110-113.

29. Hussain A, Maitra J, Khan K A. Development of biochar and chitosan blend for heavy metals uptake from synthetic and industrial wastewater [J]. Applied Water Science, 2017, 7(8): 4525-4537.

30. Sushil P, Bharti K, Kumar N. Kinetic study of lead $\left(\mathrm{Pb}^{2+}\right)$ removal from battery manufacturing wastewater using bagasse biochar as biosorbent [J]. Applied Water Science, 2018, 8(04):1-13.

31. Y. Chen, Z.J. Gong, S. S. Yang. Kinetics and thermodynamics for $\mathrm{Cu}^{2+}$ adsorption by modified corn straw $[\mathrm{J}]$. Chinese Journal of Environmental Engineering, 2013, 7(02): 523-529.

32. Y.M. Chen, J.F. Chen, research on the reclamation of solid wastes from fruit and vegetable processing [J]. Journal of Zhangzhou Institute of Technology, 2018, 20(04): 79-84.

33. F. Nv, P.J. He, L.M. Shao, et a1. Effect of ph value on fermentation pathways of biodegradable organic waste [J]. 2006, 5: 991-997. 